\title{
Male Chauvinism in Cameroon Pidgin English: The Case of the Collocates of Man
}

\author{
Valentine Njende Ubanako, ${ }^{1, *}$ \\ ${ }^{1}$ The University of Yaounde I, Cameroon. \\ *Correspondence: E-mail: ubaval@yahoo.com \\ Received: July 8, 2016 \\ Accepted: September 21, $2016 \quad$ Online Published: August 27, 2018 \\ doi:10.5430/wjel.v8n2p12 \\ URL: https://doi.org/10.5430/wjel.v8n2p12
}

\begin{abstract}
The aim of this paper is to assess the creative and dynamic uses of the collocates of man in Cameroon Pidgin English as it has picked up chauvinistic connotations in a strict and increasingly patriarchal Cameroon. Cameroon Pidgin English has been analyzed from different perspectives by different scholars, but the area of collocation has seldom been tackled. Word associations like 'speak like a man', 'drive like a man', 'man-boy', 'my man' (penis),' he is a real man' 'man hand' etc. abound in the repertoire of Cameroonian users of English. This paper thus brings out the different possible collocations with the word man as well as semantic degradations and ameliorations in the Cameroonian context and investigates if the continuous dominance of (the) man in the Cameroonian society could be a subtle case of linguistic rights violation. This study uses participant observation, interviews and questionnaires to obtain data from 100 speakers of Cameroon Pidgin English in Cameroon.This study employs the social identity theory propounded by Henri Tajfel and John Turner $(1979 ; 1986)$ which explains intergroup behaviours and status differences. Results show that the domains of use cut across the domains of the traditional ruling system, titles and kinship terms, professions, traditional economic system and foodstuffs and drinks. Also, man is used in Cameroon Pidgin English for self -expression and self- identification. Most of the collocates of man reflect the sociolinguistic background of the country with most of the terms having come from background languages like French, Cameroon Pidgin English and Camfranglais.
\end{abstract}

Keywords: Pidgin English, collocation, patriarchy, man.

\section{Introduction}

Studies on gender inequity in language use abound. Many publications in the area have seen the light of day Lakoff (1975); Lakoff (2004); Spender (1980); Carli (1990); Tannen (1990); Strand (1999); Reid et al (2003); Pennebaker et al (2003); Clopper (2005); Xia (2013). As a matter of fact, Lakoff's (1975) seminal publication, Language and Woman's Place, set the pace for research that explores the relationship between language and gender. He coined the term "woman's language" which has become very popular among researchers in the domain of language and gender studies. He notes that there is a direct correlation between the inequity in language and the inequity in men and women's social statuses. Morris (1993:15) notes that 'man' is always the positive term (the norm) and 'woman' the 'other". This has invariantly brought about issues like gender identity, gender roles and gender stereotypes. Some scholars have examined gender differences by studying the actual words used by people. Mehl \& Pennebaker (2003), Mulac et al (2001) and others, for example, in their attempt to distinguish the way women use language from men have reported that women are more likely to use more intensive adverbs, more conjunctions, more modal auxiliary verbs while men mostly use swear more, longer words, more articles, and use more references to locate. Mehl \& Pennebaker (Ibid) came up with a revealing finding that women are more likely to use the first-person singular than men.. Widdowson (1994) opines that language is naturally used to establish social identity. He goes further to indicate that conformity to the norms of a specific language variety indicates group membership. According to him, therefore, since language is a tool used by the society, the society should be allowed to shape the language to be able to respond to its environmental needs.

The word man, was originally gender neutral. About a thousand years ago, the word started to refer to a male and it was only around the late 20th century that it was almost exclusively used to refer to males. One thing remains clear; culture determines gender roles and spells out clearly our beliefs, behaviours and characteristics. This, however, varies from one society to another and from one culture to another. In most societies, language is used as a weapon 
for domination, subordination and abuse of women. This overbearing domination by men has not left the female folk indifferent as they have attempted to create a language of their own as a response to this domination; a language that will assert the woman and give her the lost dignity and consideration. This has brought about what is commonly referred in the literature as "Ecriture feminine". McConnell-Ginet (1980: xi) posits that:

Many women writers find the forms and 'the oppressor's language' they've inherited inadequate to their expressive needs. To try to create alternative modes of expression, women are experimenting with new forms of writing and speaking. Language is seen as both problematic and potentially powerful in the development of alternatives to political, aesthetic, and intellectual traditions shaped by and for men.

One of the hallmarks of the English language, apart from its spread, has been its adaptability and suitability in different contexts and situations around the world. The language has greatly influenced users and other background languages in many postcolonial settings. Skutnabb-Kangas (1988:13) used the term linguicism to refer to "Ideologies and structures that are used to legitimate, effectuate and produce an unequal division of power and resources between groups which are defined on the basis of language". In Cameroon, for example, the language has been appropriated by Cameroonian users and this has brought out a peculiar aspect about Cameroon Pidgin English; that is, there are gender issues which can be identified and accounted for.

As a matter of fact, a number of issues will be highlighted in this paper. First, Cameroon Pidgin English will be examined and an attempt made to underscore the different perceptions and approaches by different scholars in describing this variety of English and we shall equally attempt to situate it within the context or in relation to other background languages. Second, an overview of Cameroon Pidgin English will be made in order to situate the study in the mainstream of previous works of scholars. Third, the domains of use of the different collocates of the word man will be identified and classified in the light of different semantic characteristics. Fourth, the findings will be presented in relation to the ongoing debate on the dynamism of CPE and the issue of linguistic (human) rights violation.

\section{Method}

A preliminary survey was carried out including 150 informants and those who understand the socio-cultural implications of the use of the word man in Cameroon Pidgin English and could provide relevant examples were considered for final selection (100). They were carefully chosen so that at the end, there were 50 men and 50 women. At a later stage, questionnaires and interviews were administered to the respondents in order to identify, classify according to their semantic characteristics as well as sample the attitudes of users and their possible implications. This paper uses the social identity theory propounded by Henri Tajfel and John Turner $(1979 ; 1986)$ as its main theoretical premise. This theory, which was originally used in psychology, explains intergroup behaviours and status differences. Specifically, it states that members of a particular group have the capacity to discriminate in favour of the in-group where they are members or discriminate against another out-group. People in a particular society, indeed, have different social identities depending on membership and different social contexts. The theory explains that social identity is a person's knowledge of who they are based on group membership. They consider the group to which people belong to as an expression or a source of pride and self-esteem. They state that three important mental processes are involved in considering others as "us" or "them". These are social categorization, social identification and social comparison.

\section{Pidgin English in Cameroon}

Pidgin English is an important contact language in Cameroon where it exists alongside more than 285 home languages, Ethnologue (2005), two official languages, contact and hybrid languages. In the $18^{\text {th }}$ Century, the language had become a very important language used for trade and evangelisation by the plethora of colonial administrations which governed the country. Of the European nations which governed the country after the Portuguese settlers discovered the country in 1472, the most significant moments in the development of the language were the gradual replacement of a Portuguese-based Pidgin by an English-based Pidgin when Britain annexed Cameroon; the annexation of Cameroon by Germany in 1884 who initially discouraged the use of Pidgin but soon discovered how important the language was and decided to use it alongside German. During this period, Pidgin was composed of items drawn from Portuguese, indigenous languages, simplified English and German. Some researchers have equally highlighted the importance and place of Pidgin English in Cameroon and noting that since it is the language of everyday informal interactions in Cameroon, Schneider (2007). A handful of local scholars like Mbangwana (2004), Mbufung (2001), Atechi (2011) and many more, have called for the language to be used in teaching. Other scholars have, however, predicted the death of the language, Kouega (2001). Mbangwana (1983:90) considers it a 'non-ethnic language' thereby arguing that the language has a national character, while Chumbow and 
Simo (1996:419) point out that the language, more than any other, can solve the communication needs of Cameroonians. Despite their divergent views about the status of the language, they are however, unanimous that Cameroon Pidgin English is the most widely spoken lingua Franca in Cameroon and the language is waxing strong. Compared to other background languages (French, English Camfranglais, indigenous languages, etc.), Pidgin English is a great contributor to the development and spread of the Cameroon English lexicon. Anchimbe (2006:213) in an attempt to examine the relationship between CamE and CPE talks of the "narrowing gap between CamE and CPE". Equally, Sala (2005:402-8) had predicted that Cameroon Pidgin and Cameroon English seem to be moving towards a common norm. Ngefac and Sala (2006) posit that Cameroon Pidgin English and Cameroon English are at a confluence as the former is giving up most of its phonological peculiarities in favour of those of Cameroon English. Thus, as time passes, it becomes more and more difficult to draw a dichotomy between CamE and CPE. Many words and expressions which we find today in CamE have come from CPE as can be attested in the domains of commerce, preaching, social life, etc. Many CPE words have been combined with English words to give rise to compounds, blends, affixes etc. which today is part and parcel of Cam E. The influence of CPE on CamE, is also perceptible at the levels of semantics, syntax, morphology etc.

\section{Domains of Use}

The domains where man assumes its patriarchal attributes in Cameroon Pidgin English span through various domains. Some of these domains include: traditional ruling system, titles and kinship terms, professions, traditional economic system and foodstuffs and drinks.

\subsection{Foodstuffs and Drinks}

The domain of foodstuffs and drinks, provide many cases of collocations with the word man in Cameroon Pidgin English usage. These foodstuffs and drinks represent the different social and linguistic backgrounds of Cameroonians and irrespective of their origin, there is still the overt male dominance in the appellations and use of such terms. Examples of such terms pertaining to foodstuffs and drinks include the following:

Man pawpaw- male paw paw plant known not to produce fruits, but believed to be highly medicinal.

Woman pawpaw-female paw paw plant known to produce the pawpaw fruit.

One man- referred to a bottle of drink (preferably beer). Mostly used by the younger segment of the population.

Man mimbo- well fermented palm wine believed to be good only for the man as opposed to 'woman mimbo' explained below.

Woman Mimbo-freshly tapped palm wine which is not capable of making someone tipsy or drunk. Believed to be meant for women and 'weak men'.

Man kola- matured kola nut which is greatly appreciated by men. It is a source of pride to the owner especially when it is brought out to accompany palm wine

Woman kola-kola nut which is not matured enough and 'weak' like women

Man pepper-pepper, which is hot enough and spices food further.

Woman pepper-fresh and ripe pepper, which is not hot enough.

Man fowl-the male (cock) which is considered strong and owner of all the hens. It is attributed all the qualities of the man.

Woman fowl-the female (hen) which has the duty of laying eggs and producing chicks just as women give birth to children. It is attributed all the qualities of the woman.

Man goat-the male (buck or billy goat). It is considered the head and attributed all the qualities ascribed to men.

Woman goat-the female (nanny goat). It is considered weak as opposed to its male counterpart and attributed female qualities among which is giving birth.

\subsection{Professions}

There are many professions within the multilingual setup of Cameroon where there is either the lack or the under use of the feminine equivalents despite the fact that many women are also part of such professions. Some of such terms include the following:

Washerman-one who does laundry and washes cars

Church man-one who loves and is involved in church activities a lot. 
Charcoal man-one who produces and sells charcoal.

Army man-a military man

Garage man-a man who works in or owns a garage

Jujuman-a traditional healer

Bike man- a bike rider

Motor man- another name for a bike rider

Medicine man- a traditional healer

Ngambe man- a soothsayer

Headman-leader of a team or group of workers

Electric man-an electricity supply agent who works with the electricity company-ENEO or electricity technician

Water man- a water supply agent who works with the water supply company-CAMWATER or water technician

Bread man-one who produces bread or supplies it to different sales points.

Glass man-a person who deals in glass

\subsection{Kinship Terms and Titles}

Kinship terms and titles as used in Cameroon Pidgin English once more indicate that there are many collocates with the word man as opposed to collocates with the female gender. In many of these cases, the terms that have the male attribute are more elevating and dignifying. Some examples include the following:

Man pikin-a male child or a bold person.

Man boy-a brave person

Assembly man-member of parliament

Family man-a married person with children

Ngumba man-one who belongs to a secret society 'Ngumba house'

Man for compound -family head

Table 1. Domains of use

\begin{tabular}{|l|l|l|}
\hline Domain & Number & Percentage \\
\hline Foodstuffs and drinks & 13 & 38.23 \\
\hline Professions & 15 & 44.11 \\
\hline Kinship terms and titles & 6 & 17.64 \\
\hline TOTAL & $\mathbf{3 4}$ & $\mathbf{1 0 0}$ \\
\hline
\end{tabular}

From the table above, as far as different domains are concerned, the domain of professions has the highest number of collocates of man. The number of occurrences numbered 15 out of a total of 34 , accounting for $44.11 \%$, while the domain of foodstuffs and drinks followed closely with 13 cases out of 34, giving $38.23 \%$. The domain of kinship and titles had 6 occurrences accounting for 17.64\%.

\section{Semantic Characteristics}

There are perceptible semantic characteristics as far as the use of words which collocate with 'man' are concerned. They have greatly affected the meanings of the collocates giving rise to cases of semantic amelioration and semantic degradation.

\subsection{Semantic Elevation or Amelioration}

Semantic elevation or amelioration occurs when in the course of time, words pick up more prestigious meanings. The case of Squire and Mischievous have been reported in Middle English. In Cameroon Pidgin English, this is equally a reality as most of the words which collocate with man have undergone semantic amelioration and as a result, increased self-esteem and positive distinctiveness among the users. The examples below are cases of semantic amelioration:

Better man-good and understanding person 
Big man-influential and respectable person

Manpikin- male

Man hand-right hand

Money man-a rich person

Town man-a civilized person

Whiteman- fair skinned person

Whiteman woman-fair and usually beautiful woman

Chapman-one who loves women

Bookman-learned person

Man hour-late night, generally around or above midnight

Nyanga man-fashionable and showy person

Guy man-one's close friend

Ninety minute man-bosom friend. One with whom a person spends most of the time with. 'Ninety minutes' the duration of a football match.

Padi man-one's pal, one's close friend. It is very popular among the youths in Cameroon.

White man-clean or civilized. For example 'to behave like a white man'. It also refers to the white race.

Old man-refers one's father. Mostly used by the younger segment of the population

Oyibo man-white man. This term, which is originally from Igbo and very popular in Nigeria, has entered common usage in Cameroon pidgin English to refer to the same concept (the white race).

\subsection{Semantic Degradation}

Semantic degradation comes about when in the course of time, words pick up a more pejorative meaning. This will refer to the use of man in interpersonal and intergroup relations which point to negative or pejorative attributes. Examples include:

Woman motor-generally small and flashy cars

Kumba man- a cheat/fraud

Slack man-impotent/sexually weak person

Chop man-glutton

Woman colour-a shouting colour

Belle woman- a pregnant woman

Woman man- a man who behaves more like a woman, generally, a weak man

Woman wrapper-a man who loves going out with women

Banga man-one who smokes and or sells Indian hemp

Die man-a corpse

Countryman-a primitive and uncivilized person

Tifman- a thief

Woman hand- left hand, generally believed to be weaker and less active.

Ntongtu man- a person who hails from the West region of Cameroon

Air man- a weak person

Wowo man-an ugly person

Chain man-poverty stricken person

Village man- a primitive and uncivilized person

Belle man-a man with a protruding stomach 
Akwara man-a man who loves going out with many women at a time.

Yeye man-a weak person

Lie man- one who likes telling a lot of lies

Witchman-a wizard

Cunny man- cunning person

Conto man-stingy person

Bororo man-a Fulani, often despised person

Banga man-Indian hemp smoker.

Dry man-a slim person.

Suffer man-poor wretched person.

Aloman-weak person.

Mbutman-a foolish person

Table 2. Semantic elevation and degradation

\begin{tabular}{|l|l|l|}
\hline Semantic domain & Number & Percentage \\
\hline Semantic elevation & 18 & 36.73 \\
\hline Semantic degradation & 31 & 63.26 \\
\hline TOTAL & $\mathbf{4 9}$ & $\mathbf{1 0 0}$ \\
\hline
\end{tabular}

From the data on the semantic characteristics of the use of man is concerned, it stands out clear that out of the total 49 occurrences in the semantic domain, 18 cases of semantic elevation accounting for $36.73 \%$ while 31 cases of semantic degradation were identified giving $63.26 \%$. This indicates that there are more cases of semantic degradation as far as the use of man is concerned than cases of semantic elevation.

Table 3. Contribution of domains/semantic characteristics in data

\begin{tabular}{|l|l|l|}
\hline Domain/Semantic characteristic & Number & Percentage \\
\hline Foodstuffs and drinks & 13 & 15.66 \\
\hline Professions & 15 & 18.07 \\
\hline Kinship terms and titles & 6 & 7.22 \\
\hline Semantic elevation & 18 & 21.68 \\
\hline Semantic degradation & 31 & 37.34 \\
\hline TOTAL & $\mathbf{8 3}$ & $\mathbf{1 0 0}$ \\
\hline
\end{tabular}

This table summarises the weight of each domain or semantic domain in the corpus and indicates the contribution of each domain in the general data. As the table indicates, semantic degradation involving the use of man is the most productive in the corpus as it accounts for a total of 31 occurrences out of a total of 83, giving $37.34 \%$. Next to semantic degradation is semantic elevation which has yielded $21.68 \%$. Considering the fact that out of the total number of occurrences in the data, semantic characteristics account for more than half (59.02\%), it indicates that semantic characteristics are the most productive domains as far as the collocates of man are concerned. Hence, one can conclude that the collocates of man in Cameroon English mainly indicate semantic degradation and semantic elevation. The domains of professions and foodstuffs follow closely accounting for 18.08 and $15.66 \%$ respectively. Kinship terms and titles contributed the least with a total of 6 occurrences out of 83 giving a percentage of 7.22.

\section{Attitudes of men and women towards the use of man}

In order the sought the attitudes of the informants as far as the use of the word man is concerned in Cameroon Pidgin 
English, a questionnaire was issued to 50 men and 50 women). The responses are presented in the table below:

Table 4. Attitudes of the use of man by men and women

\begin{tabular}{|l|l|l|l|l|}
\hline Sex & Positive attitude & Percentage & Negative attitude & Percentage \\
\hline Male & 40 & 80 & 10 & 20 \\
\hline Female & 10 & 20 & 40 & 80 \\
\hline TOTAL & $\mathbf{5 0}$ & $\mathbf{1 0 0}$ & $\mathbf{5 0}$ & $\mathbf{1 0 0}$ \\
\hline
\end{tabular}

From the responses, it is obvious that men are conscious of the use of the word man and enjoy the power and prestige which goes with it. Out of the 50 males, 40 had a totally positive attitude scoring $80 \%$. As concerns the attitudes of women, only 10 out of 50 women (20\%) had positive attitudes advancing reasons like the man is the head of the family; God made it that way; it is nature etc., thus seeing no reason to change or look for feminine equivalents in all situations. None of them was neutral.

\section{A case of linguistic (human rights) violation?}

The 1948 Universal Declaration of Human Rights, in its preamble, expresses its "faith in fundamental human rights, in the dignity and worth of the human person and in the equal rights of men and women". In its second article, it establishes that "everyone is entitled to all the rights and freedoms" regardless of "race, colour, sex, language, religion, political or other opinion, national or social origin, property, birth or other status".

Phillipson (1992), talking about the rights of languages and their users, holds that these rights must be enjoyed and no maltreatments or unjust conditions can stand in the way of the rights. Phillipson (Ibid:94), quoting Article 27 of the International Covenant on Civil and Political Right (1966) notes that: "In those states in which ethnic, religious or linguistic minorities exist, persons belonging to such minorities shall not be denied the right, in community with the other members of their own group, to enjoy their own culture, to profess and practice their own religion or to use their own language".

From the foregoing, it is evident that under other heavens, this situation will be castigated as a blatant expression of linguistic rights violation since actually the way the attributes of man are used in Cameroon Pidgin English tends to point to that direction. Expression of the dominance of male attributes over female attributes cannot be considered a case of linguistic or human rights violation as some gender sensitive pundits may think. Considering the fact that there are also situations where the word man has picked up some negative attributes, this goes to buttress the fact that the way the word is being used in the context of Cameroon simply reflects the social and cultural distribution of roles and power within the complex multilingual and multicultural context of the country. Furthermore, everyone seems to accept the situation as no cases have been reported of either individuals or groups trying to reverse the situation.

\section{Conclusion}

In this paper, we have demonstrated that Cameroon Pidgin English is essentially patriarchal with the abundance of collocates of man which span through different contexts and situations. In Cameroon, as is the case with other societies in Africa and beyond, language has been tailored to suit the man to the detriment of the woman.

Semantic characteristics are the most productive domains where the word man is used as demonstrated in the corpus. Specifically, semantic degradation and semantic elevation accounted for most of the occurrences in the data.

It is equally evident that there are other factors which are not necessarily gender based or gender oriented, which determine the way men and women use language. Issues of power, socioeconomic status, age as well as local context can equally determine language use among men and women and this aptly applies to the situation in Cameroon Pidgin English.

There is social competition between men and women in Cameroon Pidgin English with the former doing everything to show that the latter is inferior or is a subordinate. There is thus a perceivable man/woman dichotomy in the use of most words with the man collocates standing out as stronger, more ameliorative and dignifying such as the following: man/woman kola; man/woman mimbo etc. Furthermore, words which designate women have negative connotations, even in situations where the corresponding male words designate the same state or condition for men.

It stands out clear from this paper that stereotypes still play a very strong role in the use of gender-specific terms in Cameroon Pidgin English and no matter from what perspective we view it, one thing which remains clear is the fact 
that it is a succinct contribution to the description and development of English in Cameroon and helps immensely in painting the socio-cultural landscape of Cameroon where the man is always on top.

Furthermore, there is a significant level of variation as far as beliefs and attitudes towards the use of man is concerned. From the data drawn, it is evident that the attitudes of men towards the use of the item man, in general, indicates their general attitudes towards women.

Both men and women are aware of the existence of gender neutral terms, but in their vast majority, prefer to let sleeping dogs lie. They are therefore not receptive to language reforms, advancing the protection of their socio-cultural identity as an important reason. Thus, despite the fact that the continuous use of man in many words indicates dominance and subordination, some women are comfortable with it. Such usages are not considered as having chauvinistic tendencies, but as normal usages, which portray a normal Cameroonian society where the man is the head of the family and consequently, having the upper hand in decision making.

The word man has undergone creative uses and changes in Cameroon Pidgin English usage, which stand out differently from a typical native English context and this has gone a long way to indicate the dynamism and vitality of Cameroon Pidgin English.

The word man appears in different positions and forms. In some cases, it appears in initial position while in others, it appears in a secondary position. Examples include man boy, man pikin/ngambe man, tifman. The word is written differently, which goes to call for the standardization of spelling in Cameroon Pidgin English. As such, some words are written as one word while others are written as two separate words. This generally does not follow any laid down spelling principle, but simply depends on the whims and caprices of the user.

\section{References}

Anchimbe, E. (2006). CamE: Authenticity, Ecology and Evolution. Berlin: Peter Lang

Atechi, S. (2011). Is Cameroon Pidging flourishing or dying? English Today, 27(3), 30-34. https://doi.org/10.1017/S0266078411000356

Carli, L. L. (1990). Gender, language, and influence. Journal of Personality and Social Psychology, 59, 941-951. https://doi.org/10.1037/0022-3514.59.5.941

Clopper, C., Conrey, B., \& Pisoni, D. (2005). Effects of talker gender on dialect categorization. Journal of Language and Social Psychology, 24(2), 182-206. https://doi.org/10.1177/0261927X05275741

Dennison, C. (2006). The effect of gender stereotypes in language on attitudes towards speakers. Unpublished M.A thesis, University of Pittsburg.

Ethnologue. (2005). Languages of the World, at: http://www.ethnologue.com.

Kouega, J. P. (2001). Pidgin English Facing Death in Cameroon. Terralingua. Hancock, pp. 11-22.

Kouega, J. P. ( 2006). Aspects of CamE Usage: An Introduction. Muden, Lincom Europa.

Lakoff, R. (1975). Language and Woman's Place. New York: Harper \& Row.

Lakoff, R. (2004). Language and Woman's Place. Text and Commentaries. Mary Bucholtz (ed). Oxford: Oxford University Press.

Mbangwana, P. (2004). Pidgin English in Cameroon: A Veritable Linguistic Menu. In Africa meets Europe: Language Contact in West Africa.George Echu and Samuel Gyasi Obeng (eds), Nova Science publishers, inc. pp.23-44.

Mbassi-Manga, F. (1976). The State of Contemporary English in Cameroon. In Francis Mbassi- Manga CASEF, Victoria: Pressbook. pp. 49-63.

Mbufung, P. (2001). Pidgin English in Cameroon Education. English Today, 17(3), 67. Cambridge: Cambridge University Press.

McConnell-Ginet, S., Burker, R., \& Furman, N. (Eds.) (1980). Women and Language in Literature and Society. New York: Praeger.

Mehl, M. R., \& Pennebaker, J. W. (2003). The sounds of social life: A psychometric analysis of students' daily social environments and natural conversations. Journal of Personality \& Social Psychology, 84, 857-870. https://doi.org/10.1037/0022-3514.84.4.857

Mulac, A., Bradac, J. J., \& Gibbons, P. (2001). Empirical support for the gender-as-culture hypothesis: An 
intercultural analysis of male/female language differences. Human Communication Research, 27, 121-152. https://doi.org/10.1093/hcr/27.1.121

Morris, P. (1993). Literature and Feminism. Oxford: Blackwell Publishers.

Ndoping, J. (1989). Comparative Study of Cameroon Pidgin and Standard English Grammar. Unpublished Maitrise Dissertation, University of Yaounde.

Ngefac, A. (2001). Extra-linguistic Correlates of CamE Phonology. Unpublished Ph.D, university of Yaounde I.

Ngefac, A., \& Sala, B. (2006). Cameroon Pidgin and Cameroon English at a Confluence: A real-time investigation. In English World-wide, 27(2), 217-227. John Benjamins Publishing Company.

Nkemleke, D. (2002). A corpus- based study of the modal verbs in Cameroon Written English. Unpublished Ph.D thesis, university of Yaounde I.

Pennebaker, J. W., Mehl, M. R., \& Niederhoffer, K. (2003). Psychological aspects of natural language use: Our words, our selves. Annual Review of Psychology, 54, 547-577. https://doi.org/10.1146/annurev.psych.54.101601.145041

Phillipson, R. (1992). Linguistic Imperialism. $6^{\text {th }}$ edition. Oxford University Press.

Reid, S., Keerie, N., \& Palomares. (2003). Language, gender salience and social influence. Journal of Language and Social Psychology, 22(2). Sage Publications.

Romaine, S. (1994). Language in Society: An Introduction to Sociolinguistics. Oxford: Oxford University Press.

Sala, B. (2005). Aspects of the Cameroon English sentence. Ph.D. dissertation, University of Yaounde I.

Simo Bobda, A. (1992). Aspects of CamE Phonology. Ph.D. thesis, University of Yaounde.

Skutnabb-Kangas, T. (1988) Multilingualism and the education of minority children. In T. Skutnabb-Kangas and J. Cummins (eds) Minority Education: From Shame to Struggle pp 9-44. Clevedon: Multilingual Matters.

Spender, D. (1980). Man made language. Routledge \& Kegan Paul.

Strand E. (1999). Uncovering the role of gender stereotypes in speech perception. Journal of Language and Social Psychology, 18, 86-99. https://doi.org/10.1177/0261927X99018001006

Tajfel, H., \& Turner, J. C. (1979). An Integrative Theory of Intergroup Conflict. In W. G. Austin \& S. Worchel (Eds.), The Social Psychology of Intergroup Relations. Monterey, CA: Brooks-Cole.

Tajfel, H., \& Turner, J. C. (1986). The Social Identity Theory of Inter-group Behavior. In S. Worchel \& L. W. Austin (Eds.), Psychology of Intergroup Relations. Chicago: Nelson-Hall.

Tannen, D. (1990). You Just Don't Understand: Women and Men in Conversation. New York: William Morrow.

Todd, L. (1982). Varieties of English Around the World T1: Cameroon. Heidelberg: Gross. https://doi.org/10.1075/veaw.t1

Widdowson, H. (1994). The Ownership of English. In TESOL Quarterly, 28(2), 377-389. https://doi.org/10.2307/3587438

Xia, X. F. (2013). Gender Differences in Using Language. Theory and Practice in Language Studies, 3(8), 1485-1489. https://doi.org/10.4304/tpls.3.8.1485-1489 